\title{
Del Fichero supremo a la Biblioteca de Babel: Salaverría, precursor de Borges
}

\author{
Mariano MARTÍN RODRÍGUEZ \\ Centrul de Cercetări Literare şi Enciclopedice, Universitatea "Babeş-Bolyai", \\ Cluj-Napoca (România) \\ martioa@hotmail.com
}

\begin{abstract}
RESUMEN
A juzgar por alguna declaración más bien negativa de Borges sobre la literatura española, se podría creer que esta no influyó demasiado en él. Sin embargo, existen indicios de que pudo haberse inspirado también en determinados escritores españoles coetáneos hoy casi olvidados. Uno de ellos pudo ser José María Salaverría, entre cuyos relatos destaca "El fichero supremo" (1926), del que se ha dicho que "anticipa algunas de las preocupaciones características de un tipo de relato que Jorge Luis Borges elevará años después a la máxima categoría estética". De hecho, recuerda a "La biblioteca de Babel" (1941) borgiana por su planteamiento hasta el punto de que podría pensarse que el maestro argentino pudo tener presente, a la hora de escribir esa obra maestra, ese cuento de Salaverría, el cual se publicó por primera vez en Caras y Caretas, una revista porteña que Borges reconoció "devorar" en su juventud. Sin embargo, el interés mayor de la comparación entre "El fichero supremo" y "La biblioteca de Babel" no radica tanto en el carácter de posible fuente del primero como en el contraste entre sus formas de presentación narrativa: desde fuera y en tercera persona en Salaverría, en un marco realista; y desde dentro y en primera persona, prácticamente sin marco, en Borges. Este parece desarrollar, en el registro propio de la "imaginación razonada" descrito por él mismo, una virtualidad presente en el relato de Salaverría, cuya comparación con "La biblioteca de Babel" puede suscitar también alguna reflexión sobre el enigma de la identidad y el carácter de la voz enunciadora de la biblioteca universal de Babel. Al menos, esta parece haber hecho realidad en cierto modo, de forma sublime, el patético sueño divino del archivero imaginado por Salaverría.
\end{abstract}

Palabras clave: Salaverría, Borges, biblioteca de Babel, precursor, comparación narratológica.

\section{From the Supreme Archive to the Library of Babel: Salaverría, a Precursor to Borges}

\begin{abstract}
Judging by some of the rather negative statements made by Borges concerning Spanish literature, one might be tempted to believe that the latter did not influence him greatly. However, there is evidence to suggest that he could have also been inspired by selected, now obscure, contemporary Spanish writers. One of these might have been José María Salaverría, whose story "The Supreme Archive" (1926) has been said to have "anticipated
\end{abstract}


some of the typical concerns of the kind Borges would, in later years, raise to their highest aesthetic level". It is, in fact, reminiscent of Borges' "The Library of Babel" (1941) to the point where it might be suggested that the Argentinean master, upon writing this masterpiece, had Salaverría's story in mind, which was first published in Caras y Caretas (Faces and Masks) - a Buenosairean magazine that Borges admitted "devouring" in his youth. Nonetheless, the major concern of comparison between "The Supreme Catalogue" and "The Library of Babel" does not focus only on the notion the former as a source for the latter, but rather on a contrast between their narrative strategies: third-person omniscient in Salaverría's case, with a realistic framework; and first person, practically without any framework, in Borges' case. The latter appears to have developed, in the literary mode of "reasoned imagination" as described by himself, a potential already present in Salaverría's tale, whose comparison to "The Library of Babel" can also elicit some reflection upon the enigma of identity and the character of the speaker's voice in Babel's universal library. In any case, Borges' library appears to have fulfilled, in a sublime manner, the pathetic divine dream of the archivist imagined by Salaverría.

Key words: Salaverría, Borges, library of Babel, forerunner, narratological comparison.

La afirmación de Jorge Luis Borges en El idioma de los argentinos (1928) de que "el común de la literatura española fue siempre fastidioso" (1998: 153) no ha disuadido a varios historiadores de señalar La huella española en la obra de Borges, tal como se titula un libro de Raymond H. Doyle, uno de cuyos capítulos llega a ligar la querencia filosófica de la obra borgiana con una presunta "tendencia metafísica en la literatura española" (1977: 69). Dicho estudioso observa esa tendencia sobre todo en los clásicos de la Edad de Oro, algunos de los cuales admiraba el maestro argentino sin apenas reservas, tales como Miguel de Cervantes o Francisco de Quevedo. Sin embargo, el libro es más bien vago en lo relativo a las posibles huellas de escritores españoles modernos en la obra de Borges, tal vez porque este se mostró a menudo crítico o, al menos, reticente hacia la producción literaria e intelectual española desde el romanticismo, que conocía profundamente por haberse familiarizado con ella desde muy pronto. De hecho, su erudición al respecto no era menor que sobre otras literaturas, tal como sugieren las alusiones, medidamente elogiosas, de obras no demasiado conocidas como el libro de poemas positivistas de Joaquín Bartrina Algo (1876) o los relatos "El amigo de la muerte" (1852) y "La mujer alta" (1882), de Pedro Antonio de Alarcón, que incluso llegó a prologar ${ }^{1}$. Estas obras, junto con las de Miguel de Unamuno, un autor muy leído y considerado por él, se caracterizan, entre otras cosas, por la explotación de una fantasía que juega con conceptos metafísicos (el tiempo, por ejemplo, en "El amigo de la muerte") o, en general, por la fusión íntima de literatura y filosofía. Esta

${ }^{1}$ Pedro Antonio de Alarcón, El amigo de la muerte, selección y prólogo de Jorge Luis Borges, Madrid, Siruela, 1984, pp. 9-13. 
fusión no parece muy común en la literatura española, al menos en opinión de Borges $^{2}, y$ de ahí quizá su desdén por esa literatura, cuyo énfasis frecuente en lo sentimental, lo costumbrista ("[s]u cotidianería"; Borges 1998: 153) y lo didáctico, además de su gusto por el mero artificio estilístico en detrimento de las ideas, parece distar mucho de las preferencias del autor de Ficciones. No en vano muchas de estas se distinguen por la explotación intelectual, con un estilo de una sobriedad eficaz y cristalina, del universo de la "imaginación razonada": esta se encarna en una ficción de tipo especulativo que se caracterizaría básicamente por partir de un "postulado fantástico pero no sobrenatural", según explica el propio Borges en su prólogo a La invención de Morel (1940), de Adolfo Bioy Casares, de donde proceden ambas citas (2011: 28). En el mismo prólogo, también afirma que "en español son infrecuentes y aun rarísimas las obras de imaginación razonada" (28). Sin embargo, esta declaración no parece ajustarse a la realidad. No hará falta recordar la riqueza de la fantasía razonada en la América de lengua castellana, patente en numerosos cuentos de Rubén Darío, Amado Nervo, Leopoldo Lugones, Clemente Palma, Rafael Arévalo Martínez, Enrique Méndez Calzada y otros. En España, donde la hegemonía de lo realista ha sido abrumadora hasta hace poco a efectos del canon literario oficial, esa modalidad literaria también fue abundante en las décadas anteriores a la eclosión de la narrativa borgiana, al menos en su dimensión prospectiva ${ }^{3}$ (Martín Rodríguez 2010). Incluso hubo algunas obras que presentan bastantes de las características de lo que luego se llamaría lo borgiano, hasta el punto de que no parece descabellado ligar sus ficciones más características y celebradas no solo a los modelos, reconocidos por Borges, de G. K. Chesterton o H. G. Wells (Gayton 1980, Schenkel 1999), entre otros autores anglosajones cuya fama se ha beneficiado del mayor peso de la narrativa científica y filosófica en su tradición, sino también a determinados escritores españoles modernos que pudieron servirle de ejemplo a la hora de acometer la clase de literatura que llevó a la perfección. Esos maestros peninsulares ignorados pueden considerarse precursores suyos, y no solo en el sentido de que "cada escritor crea a sus precursores" (Borges 1997: 66) al hacer triunfar unos motivos temáticos o formales cuyos precedentes se reconocen a posteriori. También en el sentido tradicional de la historia literaria, Borges tuvo predecesores españoles modernos de los que pudo extraer, conscientemente o no, materiales para su obra, tal como se ha señalado en alguna ocasión. Es el caso, por ejemplo, del planteamiento de "la vida como sueño de un ser superior" (González de la Llana 2008: 263) en Niebla (1914), de Miguel de Unamuno, y "Las ruinas circulares", de Borges, o la inspiración de este en la dramática descripción del suplicio de Miguel Servet hecha por Marcelino

\footnotetext{
2 También en El idioma de los argentinos, Borges habla del ideal de "una gran literatura poética o filosófica, favores que no se domiciliaron nunca en España"(1998: 152).

${ }^{3}$ Sobre el concepto de prospectiva en la ficción, puede consultarse Moreno 2010.
} 
Menéndez Pelayo en su Historia de los heterodoxos españoles (1880-1882) a la hora de describir, de manera más sintética (Borello 1995), el de un imaginario hereje en "Los teólogos" (1949). Asimismo, los cuentos-crítica de Azorín (José Martínez Ruiz) recopilados, por ejemplo, en Los Quinteros y otras páginas (1925), $\mathrm{y}$ muchas otras de sus numerosas ficciones metaliterarias, incluidos algunos comentarios sobre obras inexistentes, son anteriores a similares aprovechamientos por parte de Borges de personajes del acervo literario hispánico ${ }^{4}$ y universal, desde una concepción de la escritura en gran parte común (Ambrozio 1979).

A estos nombres famosos de intelectuales españoles habría que sumar seguramente otros mucho menos conocidos, pero algunas de cuyas obras anuncian tan meridianamente cuentos del maestro argentino que, para caracterizarlas, se ha invocado un anacrónico sabor borgiano. Por ejemplo, se ha afirmado del cuento "El Evangelio del Fariseo", de E. [Eduardo] Gómez de Baquero (Andrenio), que tiene una "estructura borgiana" (Pérez Cabrera 1991: 90). En efecto, este relato puede ser una muestra ortodoxa de "la escritura de notas sobre libros imaginarios" (Borges 1986: 5) que constituyen varias de las Ficciones de Borges. Gómez de Baquero imagina una tertulia en que sale a colación el descubrimiento en Egipto de un nuevo Evangelio y se describe su contenido y doctrina. Aunque al final acabe desvelándose que se trata de un fraude, el resumen y cita de ese falso evangelio es el núcleo de una ficción que no solo presiente modas actuales en la cultura de masas, sino también la explotación borgiana de doctrinas cristianas antiguas en "Tres versiones de Judas" (1944), por ejemplo. Naturalmente, a falta de alusiones de Borges a ese interesante precedente, no se puede descartar que se hubiera

${ }^{4}$ Por ejemplo, Azorín se adelantó al Borges de "El brujo postergado"(1933) en su reescritura moderna del ejemplo IX de la colección cuentística medieval El conde Lucanor, de don Juan Manuel, al haber publicado "Don Illán el mágico"en 1913 (Los valores literarios), aunque no hay constancia de que Borges lo hubiera leído. Tampoco la hay, ni siquiera la circunstancial que veremos en el caso de los cuentos que nos ocupan, de que conociera algunas narraciones modernas españolas (en castellano y en catalán) que, $a$ posteriori, se puedan considerar precursoras de otras de Borges y que constituyen una pequeña tradición poco conocida de las literaturas hispánicas peninsulares. A título al menos de curiosidad, merecen recordarse entre ellas por su calidad literaria, además de las citadas en el presente estudio, las siguientes (mencionamos asimismo la ficción del argentino que anuncien por su asunto o tratamiento): "El capricho del califa"(1894), de Emilio Ferrari "Una leyenda arábiga (Historia de los dos reyes y los dos laberintos, como nota de Burton)"(1939); "Un enigma histórico"(1923), de Azorín - "Tema del traidor y del héroe"(1944); "Ciudad futura"(1926), también de Azorín - "Utopía de un hombre que está cansado"(1975); "La novela que no escribió Cervantes"(1948), de Tomás Borrás "Parábola de Cervantes y del Quijote"(1955); "Gzwrrawtzicxm"(1965), de Nicolau Maria Rubió i Tudurí - "El informe de Brodie"(1970), o "Amb la tècnica de Lovecraft"(1956) / "Con la técnica de Lovecraft"(1970), de Joan/Juan Perucho - "There are More Things"(1975). 
producido una pura coincidencia o, todo lo más, una reminiscencia de una lejana lectura en la revista bonaerense Caras y Caretas, en la que se publicó "El Evangelio del Fariseo" el 27 de mayo de 1911 (XIV, nº 660, pp. [107-108]). Esa revista era la más leída de Argentina y, si no es apócrifa la entrevista en que se atribuye a Borges tal declaración ${ }^{5}$, este afirmó de ella lo siguiente: "Mi padre la compraba todas las semanas y la traía a casa, y yo, prácticamente me la devoraba". Así pues, no es imposible que la ficción-ensayo de Gómez de Baquero se encontrara entre los devorados por el jovencísimo Borges.

En la misma revista se publicó más adelante, cuando el escritor argentino ya había regresado a su país tras su primer y largo periplo europeo, un cuento de otro autor peninsular hoy escasamente recordado que, según una historia del cuento español del siglo XX, "anticipa algunas de las preocupaciones características de un tipo de relato que Jorge Luis Borges elevará años después a la máxima categoría estética" (Díaz Navarro y González 2002: 39). En efecto, "El fichero supremo", de José María Salaverría, puede anunciar, hasta por su título, una fícción, "La biblioteca de Babel" (1941; Ficciones, 1944), de la que el propio Borges escribió que no era "el primer autor" (1986: 5). La de Salaverría vio la luz por primera vez en Caras y Caretas el 19 de junio de 1926 (XXIX, no 1446, pp. [46-48]) y se recogió después en un volumen de la editorial Espasa-Calpe titulado El muñeco de trapo, en doble edición argentina y española, a juzgar por las fechas de las recensiones que se le dedicaron, por un lado, en el diario bonaerense La Nación (27 de junio de 1928, p. 6) y, por otro, en varios periódicos madrileños ${ }^{6}$. Esta doble publicación se explica por el hecho de que Salaverría era un escritor a caballo entre las dos orillas del Atlántico (Bernárdez 1967). Vasco como Ramiro de Maeztu y Miguel de Unamuno, se le considera compañero de estos en las filas de la llamada Generación del 98 española. Fue sobre todo periodista, aunque escribió varios libros de ensayos, en una línea crecientemente nacionalista. Vivió y trabajó en la Argentina varios años. Su estancia le inspiró un libro titulado Tierra argentina (1910), así como un interés persistente por los temas hispanoamericanos evidente en obras como Los conquistadores (1918), Bolivar, el Libertador (1930) o Vida de Martín Fierro, el gaucho ejemplar (1934). Esta última rectificó la tesis de otra anterior, El poema de la Pampa, Martín Fierro y el criollismo español (1918), que

5 Ante la imposibilidad de consultar el ejemplar físico del número 2191 (octubre de 1982) de Caras y Caretas (segunda época) en que apareció esta entrevista, su texto procede del sitio de Internet http://orquideomaidana.8k.com/Reportaje.html (15 de noviembre de 2012).

${ }^{6}$ Entre las reseñas españolas del volumen, la de E. [Esteban] Salazar Chapela en $L a$ Gaceta Literaria ( $\mathrm{n}^{\circ} 36$, p. 2) es del 15 de junio, la de J. [José] López Prudencio en $A B C$ es del 19 de junio (p. 45) y la de Juan Chabás en El Sol es del 4 de julio (pp. 6-7). De ellas, solo la de López Prudencio menciona "El fichero supremo», como hace también el autor anónimo de la crítica publicada en La Nación. 
había merecido una refutación de Borges en Evaristo Carriego (1930), donde escribió de tal libro que "el periodista o artefacto vascuence J. M. Salaverría [...] desde el título se equivoca" (Borges 1992: 156). Este exabrupto prueba al menos que su obra no le era completamente ignota al argentino, portavoz ahí de un indignado nacionalismo criollo frente al marcado nacionalismo español del vasco.

La actividad española y argentina de Salaverría, polémica a menudo a causa de sus tomas de partido, ha ocultado su valía como narrador. Además de diversas novelas y relatos más bien convencionales, sin dejar de ser muestras interesantes de su buen oficio literario (por ejemplo, el cuento "El muñeco de trapo" [1924], recogido en varias antologías, o la estimable novela psicológica La virgen de Aránzazu [1909]), escribió también varias narraciones próximas a la literatura de la "imaginación razonada". Destacan entre ellas "El planeta prodigioso" (1924), que constituye un ejemplo notable de romance científico ${ }^{7}$ (scientific romance) de raíz wellsiana, y "En la caverna encantada", publicado en Caras y Caretas en 1929, que es uno de los primeros y mejores tratamientos ficcionales del tema de la ciudad sudamericana legendaria de los Césares, de forma que el género internacional de la narrativa de razas y mundos perdidos tiene en ese relato un brillante ejemplo hispánico, que aúna aventura y pintura moderna de una especie de distopía postcolonial (Martín Rodríguez 2013: 467-471). No obstante, pese al gran interés de estos relatos, es su cuento "El fichero supremo" el que urge rescatar, habida cuenta de su posible participación en la inspiración de una de las obras maestras de Borges, pues nada impide pensar que este lo leyera en volumen o en Caras y Caretas y que su recuerdo pudiera haberse sumado a las fuentes mencionadas en "La biblioteca total" (Sur, IX, 59, 1939, pp. 13-16), esto es, en su propio ensayo luego transfigurado vertiginosamente en "La biblioteca de Babel". Esta ficción tiene como "directo antecedente" (Fernández Ferrer 2009: 31) "Die Universalbibliothek" (1904), de Kurd Lasswitz, que se presenta como la hipótesis de un profesor expuesta en una tertulia en un ambiente algo Biedermeier, haciéndose hincapié ahí sobre todo en la dimensión matemática del concepto. En esta imaginaria conversación alemana brillan por su ausencia las consideraciones trascendentales, metafísicas y religiosas, que abundan, como veremos, tanto en "La biblioteca de Babel" como en "El fichero supremo".

Este cuento salaverriano comparte con otros de El muñeco de trapo su focalización en personajes de apariencia anodina, que casi todos toman por infelices, pero que el narrador acierta a sondear, tras ganarse su confianza, de forma que descubre que estos seres de apariencia mediocre albergan una vida interior fuera de lo común articulada en torno a una manía o don de aire fantástico, aunque

${ }^{7}$ El uso del término de "romance científico», no muy común hasta ahora, sigue el ejemplo de Félix J. Palma, que así traduce scientific romance en su brillante y original recreación postmoderna del género titulada El mapa del tiempo (2008). 
no sobrenatural, pues no responde sino a un mero ejercicio de la imaginación. Esta es tanto más extraordinaria por cuanto parece equilibrar la grisura aparente mediante una vividez que da sentido a la vulgaridad de sus vidas, aun a costa de bordear una locura tranquila, insospechada para quienes los rodean. Es, por ejemplo, la historia de "El forjador de fantasmas" (1920), un inglés viudo que el narrador homodiegético conoce en un transatlántico y que es capaz de ver figuras y personajes en cualquier sitio, en las nubes, en las olas, en las bandadas de pájaros. Esa visualidad interior se presenta como una suerte de cinematógrafo cerebral que amedrenta a la vez que lo sugestiona, hasta que la visión ilusoria de la esposa muerta empuja al pasajero visionario a arrojarse al mar en un intento de reunirse con el amado fantasma entrevisto. Otra figura trágica por su morbosa creatividad mental es la de "El soñador arruinado", un pobre periodista que, según cuenta al narrador, afronta sin inmutarse todas sus humillaciones materiales y morales por su capacidad de llevar una existencia paralela y compensatoria cada noche, gracias a los ensueños, cuya clase y duración es capaz de controlar, de manera que puede disfrutar de una vida heroica que le está vedada en las horas de vigilia. Por desgracia, ese don desaparece cuando pretende, embriagándose, que llegue más rápidamente la inconsciencia reparadora. Lo intenta una y otra vez, sin que pueda recuperar su antigua capacidad, casi fantástica por lo sobrehumana. No se puede forzar a la Providencia, a quien él atribuye su poder onírico, y acaba convirtiéndose en un borrachín cualquiera, aún más vulgar y desgraciado que antes. El protagonista de "El fichero supremo" aúna en su persona la locura metódica del inglés y el desafío implícito del soñador arruinado a la divinidad, cuya existencia no postula, sin embargo, el narrador. Este se limita en los tres cuentos a presentar las figuras y su propia actitud ante ellas, de manera que la historia se centra en el personaje peculiar, aunque la perspectiva adoptada sea distanciada $\mathrm{y}$, paradójicamente, subjetiva a la vez. Es como si se nos invitara a sentirnos tan cercanos afectivamente a ese personaje como se muestra el narrador, pero guardando con todo una posición externa que impide una identificación completa y facilita, en cambio, seguir con la razón el comentario conceptual que suscita el caso psíquico inusitado, así como las implicaciones filosóficas de la idea fija del personaje central. Salaverría aplica este procedimiento con notable pericia en "El fichero supremo".

El relato tiene una estructura tripartita bien reflejada en sus tres capítulos. El primero se dedica a describir el tipo humano original. Aún más que en los otros cuentos recordados, su medianía parece ser completa. Hasta su nombre, Pedro Pérez, es de lo más común. En el mundillo de las tertulias en que se mueven tanto el personaje como el narrador, se le había clasificado pronto en la categoría de lo

${ }^{8}$ Este cuento, cuyo tema anuncia lejanamente el de "Las ruinas circulares"(1940) de Borges, se publicó también primero en Caras y Caretas (XXV, $\mathrm{n}^{\circ}$ 1265, 30 de diciembre de 1922, pp. 22-23). 
indiferente. Ni listo ni tonto, "Pedro Pérez pasó al renglón de las personas grises que no alteran la temperatura de los seres con quienes tratan" (Salaverría 1928: 111112). En ese ambiente en que había una competencia constante por mostrarse intelectualmente más brillante que los rivales, Pedro Pérez era como un accesorio, una voz en el coro que pasaba desapercibida. Sin embargo, el narrador se siente intrigado precisamente por su aire tímido y neutro y, poco a poco, va descubriendo la erudición que atesora, sobre todo en materia histórica, filosófica y literaria. Se trata de un saber desinteresado y tan silencioso como la rica biblioteca del círculo mercantil de la que es el único empleado y que nadie visita, de manera que tiene todo el tiempo del mundo para acometer la tarea de crear un archivo equivalente en su intención a la biblioteca de Babel borgiana, no tanto por su idea de partida, que ya era notoria en la época ${ }^{9}$, sino por su explotación filosófico-fantástica de la misma, predominante en el segundo capítulo del cuento de Salaverría. En este, el narrador ha amistado con Pedro Pérez lo suficiente como para que se franquee con él y lo deje penetrar en los secretos aposentos de su biblioteca, donde se ven "innumerables rótulos, cifras y señas", un "inextricable ejército de cifras" (115) en que solo puede orientarse el propio y original bibliotecario. Se trata, en efecto, de su archivo personal en forma de fichero, en cuyas papeletas "van apuntados y registrados todos los libros, todos los detalles, todos los acontecimientos, no solo de la biblioteca del Centro de Comerciantes Reunidos, sino del mundo entero" (115). La razón de tan descomunal iniciativa la da el propio Pedro Pérez al confesar que aspira a "nada menos que a fichar el Universo" (115). El narrador resume luego su método y justificación: "Para él, todo debe reducirse a síntesis, o lo que es igual, a fichas. El mundo no es otra cosa que un fichero luminoso y lógico; la cuestión está en saber interpretarlo, en reunir el número total de fichas anotadas. Una vez conseguido, el mundo sería tan inteligible y manejable como una biblioteca cualquiera" (116).

De este modo, parece que nos encontramos ante un mero proyecto positivista que supondría una correspondencia integral entre la realidad y la imagen de la misma que se puede construir mediante la ciencia. Esta se entendía también como la sistematización de los conocimientos para hacer "inteligible y manejable" el mundo mediante su archivado, partiendo de la noción de que el conocimiento objetivo y su comunicación también objetiva son posibles y de que constituyen, en consecuencia, una meta ideal irrenunciable para el estudioso, tanto en las ciencias naturales como

${ }^{9}$ Paul Otlet y Henri La Fontaine crearon en 1910 el Mundaneum, un archivo que aspiraba a reunir todo el conocimiento del mundo y clasificarlo, según el sistema decimal universal, en un Repertorio Bibliográfico Universal que llegó a sumar 18 millones de fichas. El fichero se conserva en la ciudad belga de Mons y su aspecto exterior puede recordar al descrito en su ficción por Salaverría, que bien pudo inspirarse en esta generosa iniciativa, la cual perseguía promover la paz a través del conocimiento (Levie 2006). 
en las humanas ${ }^{10}$. En relación con estas últimas, parece postularse que el pasado y la personalidad del hombre son perfectamente comprensibles y comunicables con sencillez. Pedro Pérez lleva al extremo esta convicción, al creer que unas simples fichas, breves además, pueden fijar no solo los hechos históricos que consigna en las mismas, sino también "los sucesos y las cosas que creemos circunstanciales y sin trascendencia" (117), esto es, la Historia con mayúsculas y la intrahistoria, lo cotidiano, o lo que es lo mismo, absolutamente todo lo que sucede y ha sucedido en el mundo. Asimismo, pretende encerrar las distintas individualidades en unos pocos rasgos sintéticos, haciendo coincidir la personalidad y su representación lingüística. Por ejemplo, enseña al narrador su propia ficha, con lo que nos enteramos de que este y el autor del cuento son uno y el mismo, Salaverría. La reproducción de la misma da pie así a un interesante juego de espejos que no extrañará a quienes hayan leído "Borges y yo" (1957):

José María Salaverría. Es alto y flaco. Calvo desde muy joven. Tímido. Sentido de justicia muy exagerado. Es de naturaleza doble: triste-alegre; sensual-místico; cordial-misántropo; idealista-lógico; bohemio-laborioso; aventurero-sedentario. Naturaleza en constante guerra por su duplicidad. Sensibilidad enorme; con ella casi exclusivamente se está costeando su vida de escritor. (117-118).

Esta caracterización destaca por sus contradicciones. Salaverría es un ser doble, por "naturaleza", con lo que se anula implícitamente la pretensión del bibliotecario de apresar la personalidad. Aunque Salaverría no comenta su propia descripción en este sentido, una persona que puede ser una cosa y la contraria resulta imposible de definir, de fichar con objetividad. Un cuento posterior de Salaverría desarrollaría este motivo del narrador coincidente con el autor del texto y enfrentado a la visión que otros tienen de él. En su autorretrato "Salaverría más Salaverría" (Nuevos

${ }^{10}$ La creación de bibliotecas públicas con aspiraciones totalizantes es una actividad que responde típicamente a la mentalidad positivista decimonónica. La acumulación de conocimiento en la biblioteca es un instrumento fundamental para inventoriar el universo y, por dominarlo. Según Wiefarn, "soll die Bibliothek im empiristischen Verständnis nun zum umfassenden und auf Dauer gestellten Depositorium all jenes Beobachtungs- und Tatsachenwissens werden, das sich für die angestrebte durchgängige Erforschung des Kosmos nutzbar machen lässt. [...] Die ideale Bibliothek erscheint in dieser Perspektive somit als das schrittwiese zu erstellende Inventarium der gesamten Welt, das letztere im Spiegel des schriftlichen Textes auch ihre finale Erkenntnis und Nutzbarmarchung gestattet'[en sentido empírico, la biblioteca debe convertirse ahora en un depósito completo y hecho para durar de todas y cada una de todo el saber observable y objetivo, el cual sirve para la continua exploración del cosmos perseguida. (...) La biblioteca ideal aparece, desde este punto de vista, como el inventario elaborado gradualmente del mundo entero, permitiendo su conocimiento y aprovechamiento finales en el espejo del texto escrito] (2010: 408). 
retratos, 1930), se desdobla mágicamente y puede escuchar lo que sus contertulios dicen de él cuando lo creen ausente. Las maledicencias le hacen descubrir que "un mismo individuo puede ser uno o mil en función de quien le contemple, y que por ello resulta imposible obtener una idea estable de la personalidad, ya que la suya propia resulta tan poco fiable como la de los otros" (Martín 2007: 141). En consecuencia, el positivismo psicológico no sería más que una ilusión intelectual.

Salaverría no comenta didácticamente sus ideas al respecto, aunque estas se desprendan fácilmente de la narración. Prefiere dejar a su personaje continuar caracterizando su empresa, que resulta ir mucho más allá de su positivismo aparente. Este positivismo ha pasado de impulsar una intervención activa en el mundo, mediante su justificación y la aportación de las herramientas epistemológicas e ideológicas para ello, a convertirse en una especie de misticismo laico. El amor por el saber se vuelve una vía de acercamiento a lo divino, con vistas a apresarlo mediante una reproducción analógica de su creación de acuerdo con una concepción determinista de la realidad. Sin embargo, ese determinismo ya no se funda principalmente en la confianza en unas leyes naturales tan inmutables y universales como inteligibles y comunicables, sino más bien en la idea tradicional de una divinidad única omnisciente y omnipotente, creadora de todo en su presente eterno. Según Pedro Pérez (Salaverría 1928: 118-119):

-El Universo es un conjunto de hechos que se anotan y se archivan; el gran archivero no puede ser otro que Dios. ¿Cómo nos atreveríamos a imaginar que el mundo, con todos sus fenómenos sucesivos, ha sido creado a salga lo que saliere? En tal caso la persona de Dios quedaba reducida a la de un futbolista que lanza su pelota con intento, sí, de acertar, pero que ignora cuántas vicisitudes vendrán a interponerse entre la mano lanzadora y el fin ambicionado. No. El mundo no es algo que se crea por primera vez. Si aspiramos a que el mundo posea un sentido, y si queremos realmente que exista Dios, tenemos por fuerza que aceptar la idea de que el mundo, con todos sus fenómenos, estaba previamente creado en el infinito. De otra manera, iqué mezquina y triste concepción de esta máquina del Universo! Sería como asistir a una sucesión de imprevistos, a una serie de jugadas que sorprenden al mismo tiempo a nosotros, pobres jugadores, y al dueño y presidente del campo. ¡No! Yo no consiento a mi alma que se deje seducir por una idea de Dios tan subalterna. Yo quiero un Dios más poderoso. Así, yo veo el mundo como algo que no se ha hecho ni se está haciendo; lo veo como algo igual a sí mismo, invariable, único, penetrado todo él por la infinita e invariable esencia de Dios.

A diferencia de la teología cristiana, que afirma la diferencia esencial entre lo temporal y lo eterno, entre la esfera de lo humano, ineludiblemente falible y limitada, y la de lo divino, el archivero imaginado por Salaverría cree en una correspondencia perfecta entre la realidad y su representación lingüística. En consecuencia, esta sería capaz de hacer coincidir el cosmos y el archivo. Como 
escribiría Borges en "La biblioteca de Babel", "[e]1 universo (que otros llaman la Biblioteca)" (1986: 36) es en el cuento de Salaverría un ente explicable en términos humanos, ya que simplemente habría que completar su compendiado espejo documental: "El mundo, por tanto, es una historia que va desenvolviéndose a nuestros ojos, con un número determinado de accidentes. La cuestión, ahora, se reduce a anotar esos accidentes, hasta que la humanidad logre reunir todas las fichas del gran fichero. Será como poseer al alcance de la mano la suma, el índice, la explicación del Universo" (Salaverría 1928: 119).

Esta cosmovisión es grandiosa y profundamente optimista, porque dibuja una humanidad capaz de equipararse a Dios al menos en lo tocante al conocimiento, aquí considerado en su dimensión trascendente. Ni siquiera se sugiere que haya pasado por la imaginación del protagonista que su fichero, efectivamente supremo una vez completado, podría suponer un poder igualmente máximo. Si la palabra equivale a la realidad, también podría transformarla, como sugiere el funcionamiento de la magia, al menos tal como se suele explotar esta en la literatura maravillosa. Pero Salaverría opta por permanecer en el registro realista adoptado, tal vez porque esto le sirve para deconstruir la empresa prometeica de su personaje sin renunciar ni a la verosimilitud ni a cierta identificación emocional con él. Tras haberlo presentado en el ejercicio de una actividad que se esfuerza por reducir el carácter abrumador del universo mediante su simulacro, Salaverría (esto es, el narrador) lo precipita inmediatamente desde las alturas sublimes de su pensamiento. El tercer y último capítulo castiga metafóricamente, mediante un incendio virtual, a quien abrigaba, bajo su apariencia vulgar, el heroísmo de adentrarse él solo por el camino que debía llevar a la humanidad al conocimiento total. En una noche de calentura, sufre la pesadilla de un incendio que consume sus fichas. Aunque solo era un mal sueño, Pedro Pérez cae por fin en la cuenta de que su obra estaba expuesta a cualquier contingencia, y no solo a la imposibilidad de darle cabo algún día ("la razón del mundo era precisamente el no poder llegar jamás a la conquista del fin" [121]), sino también de que había "en el mundo un agente que se llamaba azar, y contra el cual, contra su infinita estupidez, los afanes de los hombres tenían que estrellarse" (121). Este agente hacía completamente quimérico e inalcanzable su propósito. El archivo total es imposible en la esfera de lo empírico. Como don Quijote, el archivero supremo no sobrevive a esta cura de realidad que arruina su afán de penetrar el sentido del mundo. Los últimos párrafos del relato dan muestra de un patetismo de buena ley al contarnos cómo Salaverría asiste a los últimos momentos del bibliotecario e interpreta imaginativamente la palabra final que pronuncia (“¡Fichero!”) como una última reivindicación de su ideal. El buen archivero podía presentarse a Dios como un arquetipo vivo de su profesión y solicitar la realización de su sueño: "Dadme, Señor, entrada a ese divino y estupendo archivo en donde se guarda la ficha máxima, la única, aquella a cuyo respaldo está apuntada la explicación de este maravilloso lío del Universo...” (122).

Así queda reivindicada, al menos en el fuero interno del narrador que considera 
esta posibilidad como plausible, la idea del fichero supremo, aunque no fuera en los términos concebidos por su creador. La cifra de la realidad es una sola ficha, cuyo conocimiento no es para este mundo. La acumulación cuantitativa de datos solo puede dar lugar a un conocimiento parcial y engañoso, que puede suscitar una falsa confianza en las capacidades humanas, pero que resulta tan poco explicativa a la postre como la ficha dedicada al mismo Salaverría, la cual también tiene la virtud de indicarnos, por lo demás, el tenor del archivo entero en construcción. El universo es irreductible a libros y ficheros, esto es, a la mera palabra de los hombres. Solo Dios tendría la clave de su conocimiento. Esta es la elegante esperanza que cierra el relato, una esperanza que es a título hipotético, porque el autor-narrador la presenta como mera fantasía suya: el moribundo simplemente "parecía" decir lo que se le atribuye ante su próxima presencia ante Dios, con lo que la historia escapa a un didactismo primario y conserva la ambigüedad que la caracteriza. De hecho, queda a la discreción de los lectores decidir si el universo es explicable o no en definitiva, ya que el fichero supremo es quimérico, pero sí podría existir en una dimensión trascendente esa ficha que lo compendiaría todo. Por consiguiente, la empresa de Pedro Pérez puede considerarse tanto el fruto de una manía o locura tranquila como el reflejo imperfecto, por terrenal, de una sabiduría sobrehumana.

Este final, abierto en cuanto a su significado, cierra coherentemente un relato que también aprovecha con habilidad el efecto sugerente de la combinación de registros literarios distintos, con la consiguiente potencialidad de lecturas plurales. En el "El fichero supremo" predomina constantemente una atmósfera realista. La figura del archivero en su contexto cotidiano, entre tertulias y en una biblioteca que nadie frecuenta, podría aparecer en cualquier narración de (malas) costumbres españolas. Sin embargo, la exposición, directa e indirecta, de sus ideas abre perspectivas metafísicas indudables, porque lo que se ventila es nada menos que el lugar del ser humano en el universo, lo que a su vez determina un efecto estético particular propio de la mejor ficción especulativa, lo sublime. Este se deriva de la reacción que convierte en placentera la sensación abrumadora de la pequeñez humana ante la magnitud del cosmos, el cual supera hasta tal punto la capacidad (y la necesidad) humana de abarcar su medio que, según Cornel Robu, "overwhelmed by the immensity of the physical universe, man is compelled to resort to nonphysical reaction, to the idea of his free mind - a faculty standing above the senses, irreducible to nature and above it" " [abrumado por la inmensidad del universo físico, el ser humano se ve obligado a recurrir a una reacción no física, a la idea de su mente libre —una facultad por encima de los sentidos, irreductible a la naturaleza y situada por encima de esta] (2012: 30b). El fichero supremo no parece ser, desde este punto de vista, sino un intento de domeñar esa inmensidad y de ponerla al alcance del ser humano mediante una operación de la mente. Esta operación es fallida por definición, pero esto no afecta a su dimensión estética, pues el archivo resulta asimismo tan inconmensurable que, al menos como proyecto, es tan grandioso como la biblioteca de Babel borgiana, en la cual lo sublime parece ser 
el efecto estético principal. A este respecto, se puede decir que Salaverría apostó fuerte al tratar de sumar al sense of wonder de la ficción especulativa que suscita la idea del fichero máximo el sense of loss más común en la literatura llamada de mainstream o canónica, esto es, la nota de tristeza que apela a la emotividad de los lectores y que es patente en el último capítulo de la historia de Pedro Pérez, cuando su fallecimiento lo dota de una dimensión emotiva que se añade a la simpatía que Salaverría se esfuerza desde el principio del cuento por despertar hacia este personaje extravagante y algo ridículo por su quijotesco enciclopedismo, pero cuya generosidad y amor por el saber dignifican y cuya obsesión tiene visos de heroica, además de estar humanamente justificada. De este modo, Salaverría persigue explotar estéticamente a la vez lo sublime y lo afectivo, lo costumbrista y lo filosófico, en un texto que combina de forma casi inextricable registros diversos, si no contrarios, lo que constituye una hazaña no pequeña en literatura. Aunque su estilo, que es de todos modos agradable y, a ratos, hasta poético en su agradable sencillez ${ }^{11}$, no se pueda comparar con el fulgurante de Borges, "El fichero supremo" no parece desmerecer en conjunto de "La biblioteca de Babel" misma desde el punto de vista literario. Por lo menos, constituye un muy digno precursor de esta, algunos de cuyos motivos anuncia de forma más o menos clara.

La biblioteca babélica de Borges es una metáfora indiscutible, por la existencia de una correspondencia explícita, desde la primera línea del texto, con un universo cuyos signos están a la vista y que ofrece unas riquezas literalmente infinitas al afán humano de saber, pero cuya comprensión escapa ineludiblemente al hombre por la desproporción entre la totalidad casi ilimitada de los signos y el carácter finito del ser humano que ha de descifrarlos. Igual que Pedro Pérez necesitaría vivir eternamente y al abrigo de los riesgos del azar para poder llevar a término su archivo-metáfora del mundo y del tiempo (recuérdese que, en su idea, el fichero no abarcaría solo lo presente, sino también todo el pasado), Borges se refiere a figuras hipotéticas que sí serían capaces de disfrutar la biblioteca total en los términos de esta. Se trata del hipotético "Hombre del Libro", porque, "[e]n algún anaquel de algún hexágono (razonaron los hombres) debe existir un libro que sea la cifra y el compendio perfecto de todos los demás: algún bibliotecario lo ha recorrido y es análogo a un dios" (Borges 1986: 39). Ese libro-cifra parece corresponder a la ficha-cifra divina imaginada por Salaverría, que bien pudo inspirar a Borges en este extremo, igual que la ficha dedicada a cada individuo, incluido Salaverría, puede anunciar las Vindicaciones "que para siempre vindicaban los actos de cada hombre del universo" (38). No obstante, el carácter precursor de "El fichero supremo" no radica tanto en las posibles coincidencias de algunos de sus motivos con otros de

${ }^{11}$ Véase, por ejemplo, la narración simple y sumamente expresiva del fallecimiento del protagonista en la frase final del cuento: "Acto seguido, el pobre Pedro Pérez se lanzó decididamente a la aventura del Gran Viaje que no tiene vuelta" (122). 
"La biblioteca de Babel", aunque existan, como en el planteamiento común que subyace a ambas historias. Si recordamos varias de las caracterizaciones de la ficción borgiana realizadas por algunos de sus numerosísimos estudiosos, observaremos que ya están presentes en la armazón filosófico-teológica examinada de "El fichero supremo". Así, se ha escrito que "[t]he Library expresses the gap between the total perception of the world as the infinite possibility, and the time bound life of humans whose experience of a system from within prevents them from grasping its construction" [la Librería expresa la brecha entre la percepción total del mundo como posibilidad infinita y la vida sujeta al tiempo de los seres humanos, cuya experiencia de un sistema desde dentro les impide comprender su construcción] (Psarra 2005: 295), lo que tiene su equivalente en la angustia existencial que embarga a Pedro Pérez cuando se da cuenta de la imposibilidad de tener el tiempo suficiente para acabar su archivo supremo, además de preservarlo de destrucciones accidentales o deliberadas. También comparten los personajes de ambos cuentos la convicción de la posible existencia de un objeto, un libro o una ficha, capaz de contener el universo y, por ende, Dios mismo, "puisqu'en Dieu le nom et la chose coïncident (Que la lumière soit...) et que le nom de Dieu coïncide avec Dieu lui-même" [ya que, en Dios, el nombre y la cosa coinciden (hágase la luz...) y el nombre de Dios coincide con Dios mismo] (Champeau 1990: 56). Además, ese objeto, que no sería sino el vehículo de una representación lingüística, aparece dotado de una especie de anhelado poder mágico. En ambas ficciones, aunque más claramente en la de Borges, domina "el motivo temático de la búsqueda: un camino intelectivo en pos de un objeto sígnico que es el fundamento del universo de sus personajes" (Ribas-Casasayas 2000: 568). Y también en ambas, aunque el archivero y los bibliotecarios rodeen a tal objeto sígnico de un fervor casi religioso, místico incluso, "la naturaleza del objeto buscado tiene un carácter más bien cognoscitivo: la explicación del mundo" (568). Esta búsqueda "es, en última instancia, un sinsentido" (568), porque el universo por conocer es tan infinito y eterno como Dios mismo, lo que ambos protagonistas terminarán por descubrir al cabo de un proceso cognoscitivo que Borges describe con más detalle que Salaverría, pero que articula la fábula en las dos obras. Así pues, la operación conceptual realizada por Borges sobre sus precedentes meramente matemáticos ya la había efectuado antes Salaverría, con lo que el añadido borgiano no sería tan original como se ha podido creer (565):

El cuento del matemático y escritor alemán Kurd Lasswitz "La Biblioteca Universal", donde se expone la idea de producir libros mediante combinaciones tipográficas, inspiró directamente el ensayo de Borges "La Biblioteca Total", al que el autor dará una expresión literaria en el cuento que aquí se trata ["La biblioteca de Babel"], pero con un añadido original: la asimilación de esta biblioteca a la idea de un universo compuesto enteramente por libros y cuyos habitantes (los bibliotecarios) manifiestan la creencia en un libro (un conjunto de 
signos único) cuyo contenido es el fundamento explicativo del universo en el que estos personajes se mueven.

Esta descripción del procedimiento empleado por Borges en "La biblioteca de Babel" se puede aplicar casi sin cambios a su precedente salaverriano, lo que bastará quizás para sugerir al menos el interés histórico, que se suma al propiamente literario, de la ficción bibliográfica de Salaverría, cuya utilidad como punto de partida para una comparación no se limita, con todo, a la mera consignación de su carácter de posible fuente desconocida de una de las grandes narraciones del siglo $\mathrm{XX}$. El interés de esa comparación radica también en lo que nos pueda enseñar sobre la escritura de Borges y sobre la índole de su literatura especulativa. Desde este punto de vista, las diferencias estructurales entre "El fichero supremo" y "La biblioteca de Babel" son tan acusadas como sus coincidencias en cuanto al tema tratado y van mucho más allá de la explotación predominante en Salaverría del registro patético frente al sublime de la biblioteca borgiana, algo que puede observarse también en las distintas actitudes de los protagonistas tras apercibirse de la vanidad última de sus esfuerzos: la enfermedad y la muerte de un Pedro Pérez desengañado contrasta con la soledad asumida finalmente con "elegante esperanza" (Borges 1986: 41) por el enunciador babélico ante el concepto aplastante, para su insuperable limitación y pequeñez de hombre, de una biblioteca "ilimitada y periódica" (41) que subsistiría inmutable e indiferente a la futura desaparición de la humanidad. Aparte de la diferencia crucial de registro estético, "La biblioteca de Babel" se aleja también de "El fichero supremo" al desdeñar perseguir el efecto de realidad que se podría desprender de la inclusión del universo escrito en un marco encaminado a inducir una ilusión de reflejo del mundo empírico y, por ende, de una correspondencia directa entre este y el mundo imaginario de la ficción. En cambio, Borges subraya la condición fabulosa de lo enunciado mediante la omisión del marco, lo que coloca al lector ante el hecho consumado de un objeto, la biblioteca, cuya existencia se postula con independencia de lo real, como un ente ficticio autosuficiente, a diferencia de "El fichero supremo", que Salaverría presenta contextualizado en una realidad mundana que lo delimita claramente y lo reduce, en definitiva, a ser el resultado de un proceso mental ciertamente extraordinario, pero que ni altera ni cuestiona el universo que nos es familiar.

Aunque Salaverría explota hábilmente el temblor metafísico que suscita la idea misma del fichero total y divino, el marco realista que configuran de forma tranquilizadora sus elementos costumbristas, tales como las tertulias en que tanto se insiste en el primer capítulo de "El fichero supremo", permite afrontar la idea de tal archivo extraordinario desde fuera, como el fruto de una extravagancia circunscrita al protagonista, sin mayor consecuencia para la textura del universo. La misma descripción del fichero y de su autor, en tercera persona, tiende a distinguir radicalmente el objeto sígnico descrito y la dimensión ilusionista de la ficción en su conjunto, aspecto este último que queda doblemente indicado mediante la 
identificación extrema entre la voz homodiegética que presenta el marco y el propio autor de la ficción, ese José María Salaverría cuya coincidencia con el narrador del relato se hace explícita en el momento en que el escritor lee su propia ficha. Así se desactiva, al menos en parte, la potencialidad metafísica de la historia del fichero supremo y del postulado fantástico de su existencia. Esta última habría podido entrañar un comentario turbador sobre la consistencia de un universo presentado primordialmente como puro conjunto de simulacros lingüísticos, esto es, como mera representación semiótica, mientras que tal fichero y la obsesión de su creador pueden leerse perfectamente en Salaverría como una anécdota susceptible de una interpretación trascendente, pero admisible también como el informe de una rareza individual escasamente extrapolable al común de los mortales. Así pues, el marco narrativo tiende a atenuar el alcance filosófico universal de la ficción en favor de la presentación pintoresca, aunque emocionada, de un tipo curioso. Si bien es verdad que Salaverría acierta a conservar gran parte de la fuerza de la idea de Pedro Pérez, lo que acredita su pericia literaria, no lo es menos que la dimensión realista de "El fichero supremo" revela una preocupación por justificar la fábula ateniéndose a unos criterios acuñados de verosimilitud que limitan el alcance de su innovación narrativa. A este respecto, puede decirse que prolonga una antigua tradición española con la que Borges rompe decididamente, con lo que este acuña uno de los elementos originales de su producción narrativa.

Este procedimiento borgiano de omisión del marco ya figura como técnica literaria fundamental en su reescritura del apólogo del deán de Santiago y don Yllán, el mago de Toledo, de El Conde Lucanor, de don Juan Manuel. En "El brujo postergado" (Historia universal de la infamia, 1935), "Borges prácticamente se limitó a eliminar el "marco" del exemplo" (Fernández 1990: nota 4), esto es, el diálogo entre el conde Lucanor y su preceptor Patrono que abre y cierra aquel relato medieval, aclarando su significado y guiando así su lectura en un sentido moralista. En "La biblioteca de Babel", la inexistencia del marco tiene consecuencias que superan en mucho la supresión, como rasgo moderno ${ }^{12}$, de una moraleja que

${ }^{12}$ La consideración (anacrónica) de Borges como escritor postmoderno se debate con inteligencia en un ensayo de Keiser, en que la existencia de rasgos que, a posteriori, podemos considerar postmodernos en Borges no impide reconocer que "his abstract, impersonal, mystical, demanding writing unmistakably reflects its modernist foundations"'su escritura abstracta, impersonal, mística y exigente refleja inequívocamente sus fundaciones modernas] (1995: 45), las cuales pueden observarse en el hecho de que sus ficciones, incluida "La biblioteca de Babel"ilustran "the modernist fondness for artificially created, exclusive systems" [el gusto moderno por sistemas exclusivos de creación artificial] (44). Desde este punto de vista, la convivencia de sistemas no enteramente fundidos debido a la presencia del marco, colocaría "El fichero supremo"en un estadio anterior de la Modernidad narrativa, pese a rasgos claramente modernos como la reflexividad de la ficción. 
empobrecería la lectura al arrebatarle parte de su ambigüedad. En esta ficción, el espacio infinito de la biblioteca y su tiempo eterno se presentan como la única realidad posible. No parece haber nada absolutamente fuera de ella. La voz homodiegética determina una focalización en un personaje innominado que describe y analiza su entorno exclusivamente desde dentro del universo ficticio, como si no hubiera ni pudiera haber otra perspectiva posible. El mundo imaginario no se confronta pacíficamente con un mundo empírico postulado, como ocurre en "El fichero supremo", sino que aparece como el único existente, real: la biblioteca es el universo. Este universo del que no hay escape encierra a los seres que viven en él y, por procuración, a los lectores que se adentran virtualmente en la biblioteca babélica. Como consecuencia, el efecto de realidad es, paradójicamente, mayor, porque la ficción no se señala a sí misma como ficticia, a diferencia de "El fichero supremo". Al contrario, el carácter estrictamente razonado de ese universo, cuya deliberada coherencia es tal que es susceptible de análisis científico y matemático, como sugieren los estudios que se han hecho del mismo con la metodología de las ciencias duras (por ejemplo, Bloch 2008), así como su total cerrazón, construyen un artefacto ficticio autosuficiente, cuya verosimilitud no depende, a efectos funcionales, de la remisión implícita a una realidad distinta a la suya propia, y de ahí su notable solidez compositiva y la impresión creada de completitud que tanto contribuyen a atrapar al lector, si este acepta el postulado fantástico borgiano. Este se funda en la construcción de un mundo posible virtual que los lectores pueden recorrer, observar y vivir durante la lectura, cosa vedada a los visitantes del fichero supremo, el cual solo tiene, de hecho, un habitante, Pedro Pérez, porque se trata de una alucinación individual. En "La biblioteca de Babel", la alucinación, de existir, la sufren todos sus bibliotecarios, esto es, todos los hombres, si bien existen indicios que también pueden justificar una posible lectura distinta y más cercana a la idea de su posible precursor español.

"La biblioteca de Babel" tiene un aire inequívoco de ensayo, en el que los conceptos son los protagonistas, no unos personajes que solo parecen estar ahí para darles cuerpo ${ }^{13}$. La voz enunciadora parece describir con objetividad tanto la biblioteca como el propio proceso cognoscitivo que conduce a la esperanzada conclusión final, sin olvidar la historia de los distintos movimientos intelectuales que, sucesivamente, se habían ido poniendo de moda entre los bibliotecarios a fin de encontrar un sentido a tal acumulación de objetos ininteligibles, empezando por

13 “Algunos de los cuentos más logrados [de Borges] son aquellos que, valiéndose de los procedimientos narrativos tradicionales de la literatura fantástica, introducen ideas elaboradas y complejas que se transforman en la base temática principal y suscitan la acción, relegando al segundo plano a los personajes, que aparecen como sujetos pasivos en ese mundo amenazante dominado por contenidos mentales monstruosos o inhumanos"(Pérez 1995: 20). 
los libros que albergan una promesa, casi siempre incumplida, de iluminación. La enunciación de este caudal informativo adopta un aire de relación verídica que coincide con el perseguido por el discurso historiográfico, de modo que el efecto de verosimilitud fabulosa se basa también en la supuesta objetividad de la historia. De este modo, se sugiere que la biblioteca existe con independencia de los sujetos que la observan, igual que las vicisitudes de sus habitantes parecen estar dotadas de la realidad verificable que se suele expresar en la historia de nuestro mundo mediante una retórica historiográfica determinada (por ejemplo, el predominio del discurso factual, con la correspondiente ausencia de diálogos; la narración de acontecimientos de alcance general y no privado, o la omnisciencia del narrador limitada a las acciones documentadas o perceptibles desde fuera), que "La biblioteca de Babel" sigue hasta el punto de que esta ficción se presenta como una especie de memorias testimoniales. Sin embargo, un par de pasajes rompen esa ilusión de objetivismo al implicar directamente al lector en una sinécdoque reflexiva que lo asocia al predicamento metafísico expresado por el enunciado ${ }^{14}$, pero que también socava la integridad objetiva del mismo. En primer lugar, tenemos "la relación verídica de tu muerte" (Borges 1986: 38) en la enumeración de todo lo que se encuentra entre los libros de la biblioteca. Más adelante, la figura del lector irrumpe en forma de interpelación cruda: "Tú, que me lees, ¿estás seguro de entender mi lenguaje?" (40). El uso de la segunda persona del singular puede implicar ahí la existencia de un receptor que no sería el destinatario universal de un informe histórico, sino un individuo concreto al que se dirige el bibliotecario postulado y que parece introducirse en el mundo ficticio desde un exterior supuesto que se antoja imposible, al menos de aceptarse la premisa de la plena coincidencia del universo y la biblioteca. Cabe creer que tal lector fuera otro bibliotecario futuro, pero no se puede descartar que ese "tú" sea el lector de nuestro mundo enfrascado en el difícil desciframiento del lenguaje conceptual de la ficción-ensayo borgiana, en cuyo caso también cabría preguntarse por la identidad y el carácter de la voz que presenta esa biblioteca total que parece realizar el sueño del archivero imaginado por Salaverría. Si esa voz se dirige a un receptor situado fuera de la biblioteca de Babel, esta no equivaldría al todo, sino que se podría interpretar como un objeto puramente intelectual, como una ficción filosófica que se hubiera servido de una retórica determinada para asentar su efecto de realidad. Esta ficción se caracterizaría asimismo por estar dotada de una coherencia semejante a la que presenta la concepción del fichero salaverriano, cuyo desatino es perfectamente compatible con

14 "La inclusión de la cara del lector junto a la del narrador ayuda a establecer la reflexividad de la representación sinecdóquica del cuento respecto a la infinitud del universo $\mathrm{y}$, de esa forma, intensifica el sentido de intimidad metafísica entre el autor y el lector"(Ramey 2009: 3). Esta observación, referida a la ficción borgiana “El aleph”(1945) es perfectamente válida también para pasajes similares de "La biblioteca de Babel». 
la solidez que se desprende de su carácter sistemático y aparentemente razonable o, al menos, razonado, lo que constituye, pues, otro rasgo común de "El fichero supremo" y "La biblioteca de Babel".

Esta analogía entre ambas ficciones quizá no sea tan caprichosa como podría parecer a primera vista, ya que un paratexto borgiano orienta precisamente hacia la posibilidad expuesta o, al menos, implica nuestro mundo como contrapuesto al imaginario descrito, de manera que deja de ser válida, salvo como ilusión literaria (o metafísica), la mentada equiparación entre la biblioteca y el universo. La alusión en la última nota de "La biblioteca de Babel" a una amiga de Borges, Letizia Álvarez de Toledo, introduce la persona del escritor y su medio en la ficción, de manera análoga, aunque menos directa, a la manera en que Salaverría borra los límites entre las figuras del narrador y del escritor en su relato. Sin embargo, Borges no aparece como testigo en "La biblioteca de Babel". Su función es la de editar un texto ajeno, añadiéndole un par de comentarios a pie de página. El primero, que se presenta como paratexto distinto a las notas supuestas del bibliotecario babélico mediante la mención "(Nota del editor)", indica que se trata de un "manuscrito original" sin guarismos ni mayúsculas, con la puntuación limitada a la coma y el punto, antes de añadir que "[e]sos dos signos, el espacio y las veintidós letras del alfabeto son los veinticinco símbolos suficientes que enumera el desconocido" (37). Así pues, el autor del manuscrito, que se ha atenido metódicamente a las normas de su biblioteca babélica, es un "desconocido" al que nada impide atribuir una obsesión semejante a la de Pedro Pérez. Esta nota del editor constituye, en cualquier caso, un indicio de que el supuesto autor del manuscrito describe un universo diferente del nuestro, del universo real del Borges que participa en la ficción mediante esa nota, la cual puede entenderse asimismo como un ejemplo más de su adopción del cronotopo del manuscrito o testimonio encontrado, un motivo bastante frecuente en la literatura fantástica y especulativa, incluida la suya, como acreditan cuentos como "El informe de Brodie" (1970) o "La secta de los treinta" (1975). Sin embargo, el añadido de tal marco es tan discreto en "La biblioteca de Babel" que la historia puede leerse perfectamente prescindiendo de él, cosa que no ocurre en "El fichero supremo". A efectos del universo ficticio en su conjunto, es casi como si no existiera en el cuento de Borges, aunque cumpla la función de probar que la biblioteca babélica es la pura invención de un "desconocido" y no un reflejo fiel, aunque sea en forma de parábola, de un cosmos postulado fantásticamente como realidad plena en el ámbito de la historia contada. Por consiguiente, el autor ignoto de esta bien podría ser un pensador alucinado que hubiese escrito en serio la relación de su delirio filosófico, como si fuera un trasunto del Pedro Pérez salaverriano y estuviera describiendo el resultado final de la empresa bibliometafísica de este como ya realizada sub specie aeternitatis, esto es, en un tiempo y espacio tan inabarcables que habrían posibilitado el cumplimiento de sus sueños de exhaustividad y permanencia. Ese resultado último es tan sublimemente monstruoso que entraña a su vez un comentario implícito de un Borges 
profundamente agnóstico que va más allá del comprensivo escepticismo de Salaverría: la iniciativa positivista de clasificar el mundo y de expresarlo mediante el lenguaje acaba traduciéndose, al tender al infinito, en una acumulación tal de significantes que el proyecto resulta humanamente ininteligible y existencialmente absurdo. De este modo, el fichero supremo habría quedado transformado, mediante su hiperbolización irónica, en la biblioteca total, coincidiendo ambos universos sígnicos en ser puras construcciones mentales hechas por unos tipos humanos intelectualmente análogos, aunque de uno solo se predique, con sugestivo misterio, que es un "desconocido", mientras que el otro, Pedro Pérez, se caracteriza con gran lujo de detalles de acuerdo con la tradición realista a la que se atiene en mayor medida el autor español que el argentino, más innovador este en su escritura bajo la superficie clásica, académica incluso, de su estilo magistral.

Esta hipótesis, que osamos creer plausible, constituye por lo menos una posibilidad de interpretación más, entre las muchas que se han propuesto de este cuento borgiano, una posibilidad que se deduce de la comparación con su precursor y posible fuente. No obstante, se impone reconocer a este último respecto que no se puede saber con certeza si Borges, al imaginar "La biblioteca de Babel", tuvo o no presente "El fichero supremo", de forma consciente o como la reminiscencia de una lejana lectura, y que las meras coincidencias abundan en la república literaria, por lo que tampoco se pueden descartar aquí, pese a las semejanzas entre ambas ficciones ${ }^{15}$. Haya existido o no una influencia directa de Salaverría en Borges, ese parecido entre una y otra puede tener al menos la virtud de demostrar que "El fichero supremo" podría formar parte honrosa de un imaginario canon alternativo constituido, entre otros, por los predecesores y cultivadores españoles de esa literatura de la "imaginación razonada" que posee en Borges un modelo indiscutible.

${ }^{15}$ Además, "El fichero supremo"pudo inspirarse a su vez en otro precursor anterior, Jean Richepin, cuyo cuento "La Bibliothèque"(1898) presenta una estructura formal parecida a la utilizada por Salaverría: un narrador en primera persona conoce a un personaje cuyas ideas más o menos extravagantes expone este en el curso de la conversación, de acuerdo con las características fundamentales de lo que hemos denominado "etopeya dialógica"(Martín Rodríguez 2015: 30-50) al hilo de "El fichero supremo"en nuestra reedición del texto. En esta ficción de Richepin, el personaje peculiar así autorretratado filosóficamente es un bibliotecario erudito que dice haber juntado una biblioteca metódicamente completa, con las obras esenciales de cada materia ordenadas mediante una clasificación objetiva, basada en la forma y colores de su encuadernación. Al final, el bibliotecario entrega a su interlocutor y narrador homodiegético un pequeño volumen, en el que dice estar condensado todo el pensamiento humano. Tal cifra del saber humano "se composait d'un cahier de papier blanc”[consistía en un cuaderno de papel blanco] (Richepin 1996: 154). 


\section{BIBLIOGRAFÍA}

AMBROZIO, Leonilda.

1979 “Azorín em Jorge Luis Borges?”, Revista Letras, 28, pp. 185-192.

BLOCH, William Goldbloom.

2008 The Unimaginable Mathematics of Borges' Library of Babel. Oxford: Oxford University Press.

BORELLO, Rodolfo A.

1995 "Menéndez Pelayo, Borges y Los teólogos", Cuadernos hispanoamericanos, 539-540, pp. 177-184.

BORGES, Jorge Luis.

1982 "Borges: "Yo creo que podemos seguir hundiéndonos infinitamente"“", Caras y Caretas, 2191, disponible en http://orquideomaidana.8k.com/Reportaje.html (15 de noviembre de 2012).

1986 Ficciones. El aleph. El informe de Brodie. Caracas: Ayacucho.

1992 Obras completas (1923-1936). Barcelona: Círculo de Lectores.

1997 Otras inquisiciones. Madrid: Alianza.

1998 El idioma de los argentinos. Madrid: Alianza.

2011 Miscelánea. Barcelona: Debolsillo.

CHAMPEAU, Serge.

1990 Borges et la métaphysique. Paris: Vrin.

DÍAZ NAVARRO, Epicteto y José Ramón GONZÁLEZ.

2002 El cuento español en el siglo XX. Madrid: Alianza.

DOYLE, Raymond H.

1977 La huella española en la obra de Borges. Madrid: Playor.

FERNÁNDEZ, Teodosio.

1990 "Jorge Luis Borges frente a la literatura española", en Jaime Alazraki (ed.), España en Borges. Madrid: El Arquero, pp. 23-37.

FERNÁNDEZ FERRER, Antonio.

2009 "Borges y sus precursores", Letras Libres, 11, 128, pp. 30-31. GAYTON, Gillian.

1980 "Jorge Luis Borges y G. K. Chesterton", en Evelyn Rugg y Alan M. Gordon (eds.), Actas del Sexto Congreso Internacional de Hispanistas, celebrado en Toronto del 22 al 25 de agosto de 1977. Toronto: University of Toronto, pp. 312-315.

GONZÁLEZ DE LA LLANA FERNÁNDEZ, Natalia.

2008 "El sueño de un dios: la estructura narrativa en Niebla de Unamuno y "Las ruinas circulares" de Borges", Anales de Literatura Hispanoamericana, 37, pp. 263-274. 
KEISER, Graciela.

1995 "Modernism/Postmodernism in "The Library of Babel": Jorge Luis Borges's Fiction as Borderland", Hispanófila 115, pp. 39-48.

LEVIE, Françoise.

2006 L'homme qui voulait classer le monde. Paul Otlet et le Mundaneum. Bruxelles: Les Impressions Nouvelles.

MARTÍN, Rebeca.

2007 "Entre la obscenidad del yo y la reivindicación de la identidad. 'La muerte de mi doble' y 'Salaverría más Salaverría', de José María Salaverría”, Salina, 21, pp. 137-142.

MARTÍN RODRÍGUEZ, Mariano.

2010 "Science Fiction as Mainstream Literature: The Spanish Scientific Romance and its Reception before the Spanish Civil War", Foundation, 39, 110, pp. 38-59.

2013 "Longing for the Empire? Modernist Lost-Race Fictions and the Dystopian Mode in Spain", Science Fiction Studies, 40, 3, pp. 463479.

2015 "Una (post)modernidad insospechada: las ficciones fantásticas y especulativas de José María Salaverría”, en José María Salaverría, Ciencia ficción, fantasía y aventuras. Colmenar Viejo: La biblioteca del laberinto, pp. 7-85.

MORENO, Fernando Ángel.

2010 Teoría de la Literatura de Ciencia Ficción. Poética y retórica de lo prospectivo. Vitoria: Portal.

PÉREZ, Alberto Julián.

1995 "Génesis y desarrollo de los procedimientos literarios en la obra literaria de Jorge Luis Borges", en Karl Alfred Blüher y Alfonso de Toro (eds.), Jorge Luis Borges: Variaciones interpretativas sobre sus procedimientos literarios y bases epistemológicas. Frankfurt am Main-Madrid: Vervuert-Iberoamericana, pp. 11-26.

PÉREZ CABRERA, José Manuel.

1991 Andrenio: Gómez de Baquero y la crítica literaria de su época. Madrid: Ayuntamiento de Madrid-Turner Libros.

PSARRA, Sophia.

2005 "(Th)reading the Library: Architectural, Topological and Narrative Journeys in Borges' Library of Babel", en Proceedings of the International Space Syntax Symposium V. Delft: Delft Technical University, pp. 293-307.

RAMEY, James.

2009 "La sinécdoque reflexiva en la obra de Jorge Luis Borges", El Cuento en Red, 20 (2009), pp. 1-13, disponible en 
http://bidi.xoc.uam.mx/tabla_contenido_fasciculo.php?id_fasciculo $=400$ (15 de noviembre de 2012 ).

RIBAS-CASASAYAS, Alberto.

2000 "Signos mágicos de lo absoluto: aproximación a términos y conceptos de filosofía del lenguaje en tres cuentos de Jorge Luis Borges", Neophilologus, 84, pp. 555-574.

RICHEPIN, Jean.

1996 "La Bibliothèque", en Le Coin des fous. Paris: Séguier.

RoBU, Cornel.

2012 "'A Key to Science Fiction': Revisiting the Sense of Wonder", Hélice II, 1, pp. 29-37, disponible en http://www.revistahelice.com/revista/Helice_1_vol_II.pdf (15 de noviembre de 2012).

SALAVERRÍA, José María.

1928 "El fichero supremo", en El muñeco de trapo. Madrid: EspasaCalpe, pp. 111-122.

SCHENKEL, Ermar.

1999 "The Map and the Maze: H.G. Wells and J.L. Borges", en Alonso de Toro y Fernando de Toro (eds.), El siglo de Borges: homenaje a Jorge Luis Borges en su centenario, I. Madrid-Frankfurt am Main: Iberoamericana-Vervuert, pp. 357-370.

WIEFARN, Markus.

2010 "Die Bibliothek als Generalarchiv: Empirie, Demokratie und Borges' List der Kombinatorik", Weimarer Beiträge 56, 3, pp. 404420 . 